\title{
Potencial Competitivo de Biótipos de Azevém (Lolium multiflorum) ${ }^{1}$
}

\author{
Competitive Potential of Ryegras (Lolium multiflorum) Biotypes
}

\author{
FERREIRA, E.A. ${ }^{2}$, CONCENÇO, G. ${ }^{3}$, SILVA, A.A. ${ }^{4}$, REIS, M.R. ${ }^{3}$, VARGAS, L. $^{5}$, VIANA, R.G..$^{3}$, \\ GUIMARÃES, A.A. ${ }^{6}$ e GALON, L. ${ }^{3}$
}

\begin{abstract}
RESUMO - Objetivou-se com este trabalho avaliar a capacidade competitiva entre biótipos de azevém resistente e suscetivel ao glyphosate, bem como a interferência deles, em diferentes densidades, sobre o crescimento de plantas de trigo. No momento da colheita, aos 50 dias após a emergência do azevém, avaliaram-se o número de perfilhos, a altura de plantas e a área foliar. Nessa mesma ocasião, coletou-se a parte aérea e as raízes das plantas de trigo e de azevém resistente e suscetivel, determinando-se a seguir a massa seca desse material em partes separadas (raiz, caule e folhas). Com base nos dados avaliados, as seguintes variáveis para o trigo e para os biótipos de azevém foram calculadas: taxa de crescimento da cultura (TCC $=\mathrm{MS}_{\mathrm{A}} / \mathrm{N}_{\text {dias }}$ ), em que $\mathrm{MS}_{\mathrm{A}}$ é a massa seca da parte aérea e $\mathrm{N}_{\text {dias }}$ é o período em dias entre a emergência e a colheita das plantas; área foliar específica ( $\mathrm{SLA}=\mathrm{A}_{\mathrm{f}} / \mathrm{MS}_{\mathrm{f}}$ ), em que $A_{f}$ é a área foliar e $M_{\mathrm{f}}$ é a massa seca foliar; e o indice de área $\left(\mathrm{IAF}=\mathrm{A}_{\mathrm{f}} / \mathrm{S}_{\mathrm{t}}\right)$, sendo $\mathrm{S}_{\mathrm{t}}$ a superficie de solo, indicando qual a área de folhas por $\mathrm{m}^{2}$ de solo. As características avaliadas altura de planta, massa seca e área foliar dos biótipos de azevém suscetivel apresentaram menor tendência de redução e maior plasticidade fenotípica, com o incremento da densidade de plantas por área em relação aos biótipos resistentes. Com relação à competição dos biótipos de azevém com plantas de trigo, efeito negativo sobre a cultura também foi observado quando esta se encontrava sob interferência do biótipo suscetivel. Conclui-se que o biótipo suscetivel de azevém é mais competitivo que o resistente.
\end{abstract}

Palavras-chave: resistência, Lolium multiflorum, competição.

\begin{abstract}
The objective of this work was to evaluate the competitiveness of ryegrass biotypes resistant and susceptible to glyphosate, as well as their interference in wheat growth at different densities. At harvesting, 50 days after emergence, tillering, height, and leaf area of ryegrass plants were evaluated and shoot and roots of ryegrass and wheat were collected and their root, stalk and leaf dry mass was determined. Based on the data, the following variables were evaluated for ryegrass and wheat: crop growth rate (TCC $\left.=M S_{A} / N_{\text {days }}\right)$, with $M S_{A}$ being shoot dry mass and $N_{\text {days }}$ the number of days between emergence and plant harvesting; specific leaf area (SLA $=A_{f} /$ $\left.M S_{f}\right)$, with $A_{f}$ being the leaf are and $M S_{f}$ leaf dry mass; and leaf area index (IAF $\left.=A_{f} / S_{t}\right), S_{t}$ being soil area, indicating leaf area per soil area. Plant height, dry mass and leaf area of the susceptible ryegrass showed smaller reductions and better phenotypic plasticity, in function of the increasing density per soil area, compared to the resistant one. The susceptible biotype showed to be more competitive and its interference in wheat development was more visible at lower densities. It was concluded that the susceptible ryegrass biotype is more competitive than the resistant one.
\end{abstract}

Keywords: resistance, Lolium multiflorum, competition.

1 Recebido para publicação em 9.12.2006 e na forma revisada em 15.1.2008.

2 Pós-Doutorando do Dep. de Fitotecnia - DFT, Universidade Federal de Viçosa - UFV, 36570-000 Viçosa-MG, <evanderalves@yahoo.com.br>. ${ }^{3}$ Doutorando do DFT-UFV; ${ }^{4}$ Professor do DFT - UFV; ${ }^{5}$ D.Sc., Pesquisador da Embrapa Trigo, Caixa Postal 451, Passo Fundo, RS, 99001-970, <vargas@cnpt.embrapa.br>. ${ }^{6}$ Engenheira-Agrônoma - UFV. 


\section{INTRODUÇÃO}

O azevém é considerado importante planta daninha em culturas de trigo, soja e em pomares de macieira e pereira na região Sul do Brasil, porém de fácil controle (Roman et al., 2004; Vargas et al., 2004). Todavia, em decorrência do uso repetitivo do glyphosate para o controle dessa espécie infestante na referida região, promoveu-se a seleção de biótipos resistentes a esse herbicida (Vargas et al., 2004), transformando o manejo dessa planta daninha em problema de dificil solução. A fim de buscar alternativas para esse problema, tornou-se necessário realizar estudos básicos sobre a biologia e, principalmente, sobre a capacidade competitiva dos biótipos de azevém suscetível e resistente ao glyphosate.

A competição é a luta que se estabelece entre a cultura e as plantas de outras espécies ou entre biótipos da mesma espécie existentes em um local, principalmente por água, luz, nutrientes e espaço (Radosevich et al., 1996). Estudos preliminares realizados por Ferreira et al. (2006) evidenciaram que o biótipo resistente de azevém que ocorre na região Sul do País possui menor capacidade competitiva do que o biótipo suscetível ao glyphosate. Essa capacidade competitiva de uma planta sobre outra afeta negativamente a quantidade e a qualidade da produção, bem como a eficiência de aproveitamento dos recursos do ambiente. Essas diferenças no poder competitivo entre biótipos normalmente estão relacionadas às características fisiológicas, associadas ao uso da água pelas espécies vegetais (Sinclair et al., 1975; Melo et al., 2006).

Nos ecossistemas agrícolas, as plantas daninhas freqüentemente levam vantagem competitiva sobre as cultivadas. Atribui-se essa característica aos programas de melhoramento genético, os quais têm procurado desenvolver cultivares que, com pequeno porte e pouco crescimento vegetativo, apresentem elevado acúmulo de fotoassimilados em sementes, frutos, tubérculos ou outras partes de interesse econômico. Com freqüência, esse acréscimo na produtividade econômica da espécie cultivada é acompanhado por decréscimo no potencial competitivo (Pitelli, 1985).

Dentre os fatores que determinam a maior competitividade das plantas daninhas sobre as culturas, destacam-se seu porte e sua arquitetura; a maior velocidade de germinação e estabelecimento da plântula; a maior velocidade do crescimento e maior extensão do sistema radicular; a menor suscetibilidade das espécies daninhas às intempéries climáticas, como veranicos e geadas; e a maior capacidade de produção e liberação de substâncias químicas com propriedades alelopáticas (Silva et al., 2007).

Estudos sobre competitividade de culturas com plantas daninhas permitem desenvolver estratégias para seu manejo, pois podem definir as características que confiram maior habilidade competitiva às culturas (Fleck et al., 2006). A habilidade competitiva se caracteriza pela dominância de um indivíduo sobre seus vizinhos, os quais utilizam, simultaneamente, um mesmo recurso com limitada disponibilidade (Aarssen, 1983). A habilidade competitiva pode ser analisada, quanto aos efeitos, sob dois aspectos: supressão do crescimento de vizinhos e tolerância à presença de vizinhos (Goldberg \& Landa, 1991). Em sistemas agrícolas, o efeito supressivo deve preponderar em relação à tolerância das culturas, por reduzir a matéria seca e a produção de sementes das plantas daninhas e beneficiar seu manejo nas culturas subseqüentes (Jordan, 1993).

O herbicida mais utilizado atualmente no mundo é o glyphosate, que tem sido aplicado de forma repetitiva em uma mesma área várias vezes por ano; em conseqüência, casos de resistência a esse produto estão sendo relatados em diversos países. O primeiro caso de resistência de plantas daninhas a esse herbicida foi de Lolium rigidum, na Austrália, registrado em 1996. Dez anos após constatou-se a resistência a esse herbicida em outros dez biótipos em oito países, sendo eles: Amaranthus palmeri, Amaranthus rudis, Ambrosia artemisiifolia, Eleusine indica, Conyza canadensis, Lolium multiflorum, Conyza bonariensis, Euphorbia heterophylla, Sorghum alepense e Plantago lanceolata (Weed Science, 2006). No Brasil, foram registrados até o momento três casos de plantas daninhas resistentes ao glyphosate: Lolium multiflorum (azevém), Conyza canadensis (buva) e Coniza bonariensis (buva). Biótipos de azevém resistentes ao glyphosate se constituem em um grave problema nas lavouras de soja 
transgênica, trigo e pomares no Rio Grande do Sul, levando a um considerável aumento nos custos de produção (Vargas et al., 2005).

Objetivou-se com este trabalho avaliar a capacidade competitiva entre biótipos de azevém resistente e suscetivel ao glyphosate, assim como a interferência deles sobre o crescimento de plantas de trigo, visando oferecer subsídios para estratégias de manejo desses biótipos.

\section{MATERIAL E MÉTODOS}

O experimento foi realizado em ambiente protegido e com irrigação automática, em delineamento de blocos casualizados com arranjo fatorial 2 × 6 (biótipos resistente e suscetivel de azevém ao glyphosate foram cultivados em seis densidades: $0,1,2,3,4$ e 5 plantas por vaso, equivalendo a $0,10,20,30,40$ e 50 plantas $\mathrm{m}^{-2}$ ), com quatro repetições. As unidades experimentais constaram de vasos com seis litros de substrato (composto de Argissolo Vermelho-Amarelo, corrigido e adubado de acordo com análise de solo e recomendações para trigo). Na periferia das unidades experimentais foram cultivados os biótipos de azevém suscetível ou resistente ao glyphosate em diferentes densidades, dependendo do tratamento; no centro da parcela, cultivou-se o trigo (Figura 1).

Aos dez dias após a emergência das plantas (biótipos de azevém ou trigo), fez-se o desbaste conforme os tratamentos e, aos 50 dias após a emergência, a colheita do experimento. A área de semeadura do trigo no centro da parcela foi delimitada por um anel de $3 \mathrm{~cm}$ de diâmetro por $1,5 \mathrm{~cm}$ de altura, inserido no solo, de forma que a borda superior ficasse rente à

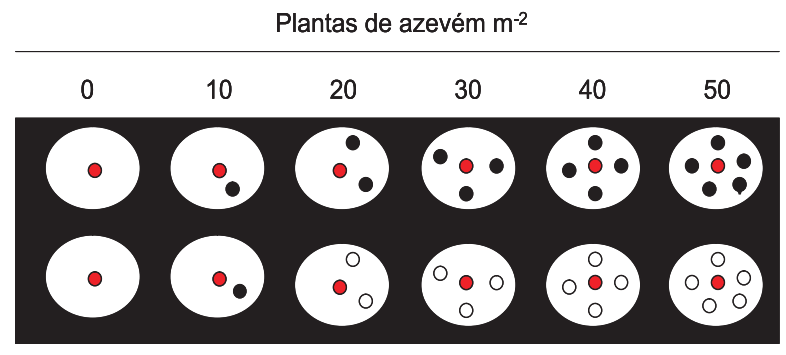

Figura 1 - Biótipos de azevém resistente e suscetível ao glyphosate em diferentes densidades, competindo com plantas de trigo: $\bullet$ trigo, $\bullet$ biótipo de azevém resistente e $\circ$ biótipo de azevém suscetível. superficie, permitindo total desenvolvimento das raízes e da parte aérea da planta e plena competição do biótipo central com as demais plantas da periferia, tanto na parte aérea como no sistema de raízes.

Durante a condução do experimento, os vasos foram mantidos na mesma distância, de forma que a área de superfície disponivel para o desenvolvimento das plantas correspondesse à área da unidade experimental.

No momento da colheita, foram avaliadas as variáveis: número de perfilhos, área foliar, massa fresca, altura de plantas e volume de raízes, para a cultura do trigo; e número de perfilhos, altura de plantas e área foliar, para os biótipos resistente e suscetivel de azevém ao glyphosate. A massa seca da parte aérea e das raízes das plantas de trigo e a dos biótipos de azevém foram determinadas por pesagem em balança analitica, após secagem desses materiais em estufa de circulação forçada de ar mantida à temperatura de $70^{\circ} \mathrm{C}$, até peso constante. A partir dos dados primários, foram ainda calculadas as seguintes variáveis, tanto para o trigo quanto para os biótipos de azevém: taxa de crescimento da cultura $\left(\mathrm{TCC}=\mathrm{MS}_{\mathrm{f}} /\right.$ $\mathrm{N}_{\text {dias }}$ - g plantas ${ }^{-1} \mathrm{~m}^{-2}$ ), em que $\mathrm{MS}_{\mathrm{f}}$ é a massa seca final e $\mathrm{N}_{\text {dias }}$ é o número de dias que a planta cresceu; área foliar específica $\left(\mathrm{SLA}=\mathrm{A}_{\mathrm{f}} / \mathrm{MS}_{\mathrm{f}}\right.$ - $\left.\mathrm{m}^{2} \mathrm{~g}^{-1}\right)$; e índice de área $\left(\mathrm{IAF}=\mathrm{A}_{\mathrm{f}} / \mathrm{S}_{\mathrm{t}}\right)$, indicando qual a área de folhas por $\mathrm{m}^{2}$ de solo.

Todos os dados foram submetidos à análise de variância, e os modelos de regressão foram escolhidos com base na significância dos coeficientes de regressão, do coeficiente de determinação e do fenômeno biológico em estudo. Para interpretação dos resultados, os dados referentes a número de perfilhos, área foliar, massa fresca, massa seca caulinar, massa seca foliar, massa seca da parte aérea e volume de raízes das plantas de trigo e dos biótipos de azevém foram transformados em porcentagem relativa à média da testemunha.

\section{RESULTADOS E DISCUSSÃO}

Quanto à capacidade competitiva de biótipos de azevém suscetivel e resistente ao glyphosate com o trigo, observou-se ajuste adequado ( $\mathrm{p}<0,001$ e $\mathrm{p}<0,005$ ) entre porcentagem de perfilhos, massa fresca, massa seca 
caulinar, massa seca foliar, massa seca total, área foliar, altura de plantas e volume de raízes de azevém em diferentes densidades, competindo com plantas isoladas de trigo, representado por modelos potenciais (Figura 2).

Observou-se tendência de redução da porcentagem de perfilhos dos biótipos de azevém com o aumento da densidade de plantas, tanto para o biótipo resistente quanto para o suscetível ao glyphosate. Todavia, esse efeito foi mais perceptivel no biótipo suscetivel (Figura 2). Erasmo et al. (2003), trabalhando com Cyperus esculentus, constataram que densidades diferenciadas dessa espécie provocaram efeito sobre o perfilhamento de plantas de arroz irrigado, após 60 dias de convivência com a cultura. $\mathrm{O}$ incremento da densidade entre gramíneas favorece a redução de emissão do número de perfilhos e estimula o crescimento em altura das plantas, o que favorece a captação de luz (Fleck et al., 2006).

Nas menores densidades de cultivo, o azevém (biótipo resistente) apresentou maior porcentagem de massa fresca total em relação ao biótipo suscetivel, porém nas densidades mais elevadas a porcentagem de massa fresca entre os dois biótipos tendeu a se igualar (Figura 2). Quanto aos efeitos isolados sobre as variáveis massa seca caulinar, massa seca foliar, massa seca da parte aérea, área foliar, volume de raízes e altura de plantas, observouse tendência semelhante, ou seja, redução para os dois biótipos com o aumento da densidade de plantas, ressaltando-se que, para o biótipo resistente, essa redução foi maior em todas as densidades. Esse fato pode ser explicado pelo fato de que o biótipo resistente apresentou maior porcentagem de área foliar que o suscetivel nas menores densidades de plantas e que, com o incremento da densidade, o biótipo resistente tendeu a apresentar maior redução de sua área foliar. Torna-se evidente neste trabalho que o biótipo suscetivel possui maior capacidade competitiva que o resistente. Isso ocorre porque o biótipo suscetível é menos prejudicado pelo aumento da densidade de plantas do mesmo biótipo ou do resistente. Esses resultados estão de acordo com os observados por Ferreira et al. (2006), os quais verificaram que o biótipo suscetível, em condições normais, em alta densidade e isento da aplicação de glyphosate, é mais competitivo que o resistente, sendo, dessa forma, dominante na população. Parks et al. (1996) verificaram que biótipos de Amaranthus retroflexus e de Chenopodium album sensiveis às triazinas apresentaram maior área foliar, altura e produção de sementes. Com relação à estatura, plantas altas demonstram maior competitividade com as demais plantas, devido à vantagem obtida na captação de radiação solar, em relação a plantas mais baixas (Fleck, 1980). Freqüentemente, plantas mais altas apresentam competitividade superior, sendo a matéria seca utilizada como indicadora dessa maior capacidade competitiva (Fleck et al., 2006). Segundo estes autores, em geral, plantas que produzem mais matéria seca causam maior redução de recursos do meio, podendo resultar na supressão do crescimento de plantas vizinhas.

No que se refere aos efeitos do azevém sobre o trigo, foi observado ajuste adequado $(\mathrm{p}<0,001$ e $\mathrm{p}<0,005)$ entre as porcentagens de perfilho, da massa seca caulinar, da massa seca foliar, da massa seca da parte aérea, da área foliar e da altura de plantas de trigo isoladas, competindo com plantas de azevém em diferentes densidades (Figura 3). Observou-se que plantas de trigo em competição com os biótipos resistente e suscetivel de azevém mostraram tendência de redução das porcentagens de perfilho, de massa seca caulinar, de massa seca foliar, de massa seca da parte aérea, de área foliar e de altura de plantas. Todavia, quando as plantas de trigo competiram com o biótipo resistente, o decréscimo nessas variáveis tendeu a ser menor do que quando a competição ocorreu com plantas do biótipo suscetivel, exceto para porcentagem de massa seca caulinar, em que o biótipo suscetível apresentou menor redução (Figura 3). Considerando que o biótipo suscetivel mostrou menor decréscimo na maioria das variáveis avaliadas com o aumento na densidade de plantas, provavelmente ele causou maior redução de recursos do meio do que o biótipo resistente, resultando em menor crescimento das plantas de trigo. Fleck et al. (2006) observaram que a presença do nabo durante os primeiros 60 dias do ciclo da soja reduziu a estatura de planta, a área foliar, a massa seca da parte aérea, a emissão e o crescimento de ramos. Em plantas de feijão, trigo e arroz, o rápido crescimento 

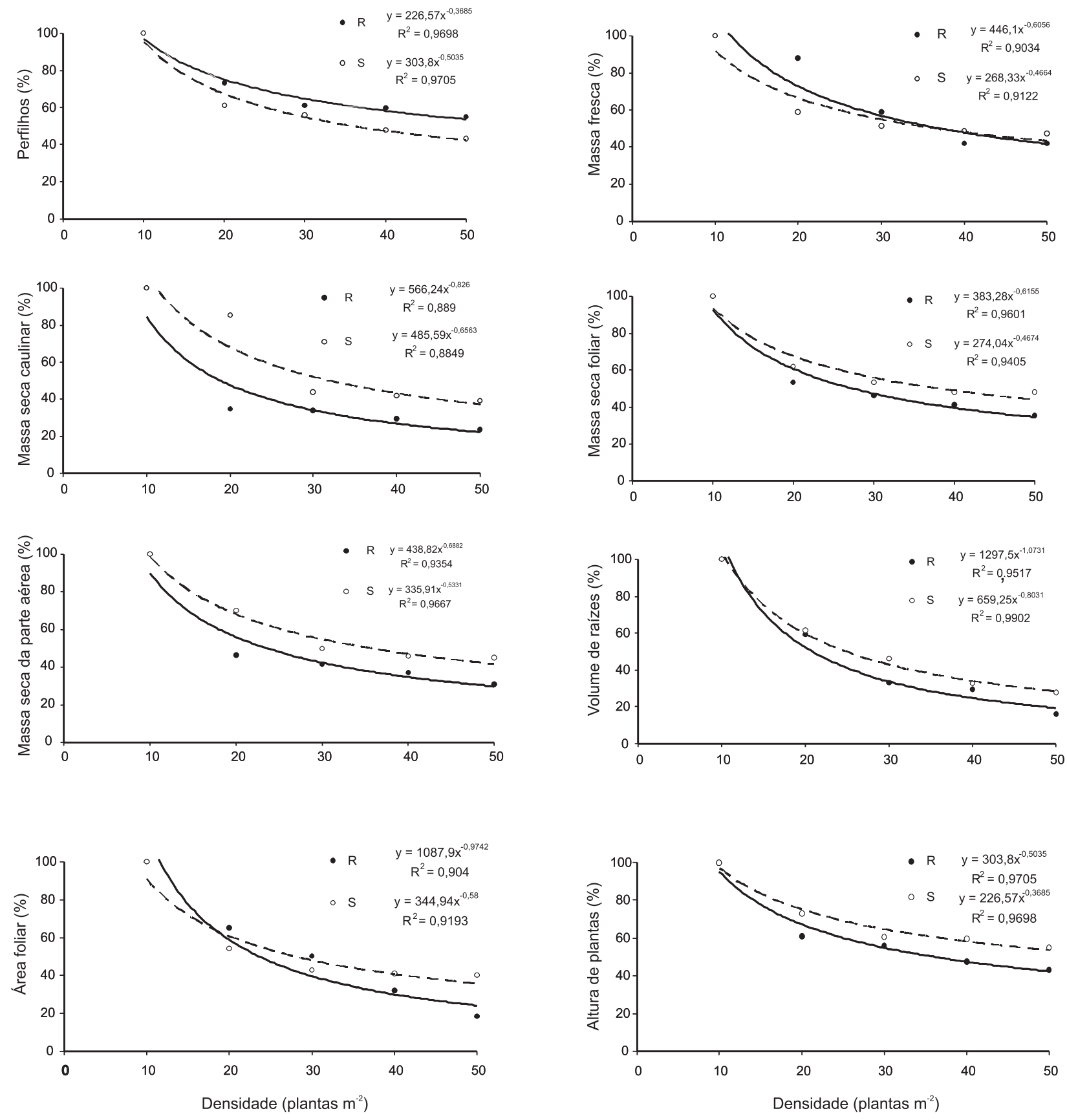

Figura 2 - Porcentagem de perfilhos, massa fresca, massa seca caulinar, massa seca foliar, massa seca da parte aérea, área foliar, volume de raízes e altura de plantas de azevém em diferentes densidades, competindo com plantas isoladas de trigo.

na fase inicial de desenvolvimento propiciou maior competitividade dessas espécies em relação às infestantes (Wortmann, 1993; Lemerle et al., 1996; Balbinot Jr. et al., 2003).

As curvas de taxa de crescimento da cultura (TCC), área foliar específica (SLA) e índice de área foliar (IAF) de azevém em diferentes densidades, competindo com plantas isoladas de trigo, apresentaram ajuste $(\mathrm{p}<0,001$ e $\mathrm{p}<0,005)$, sendo representadas por modelos potenciais (Figura 4). Constatou-se, observando as curvas de TCC, SLA e IAF, redução nessas três variáveis com o aumento da densidade de plantas de azevém em ambos os biótipos aos 50 dias após a emergência das plantas 

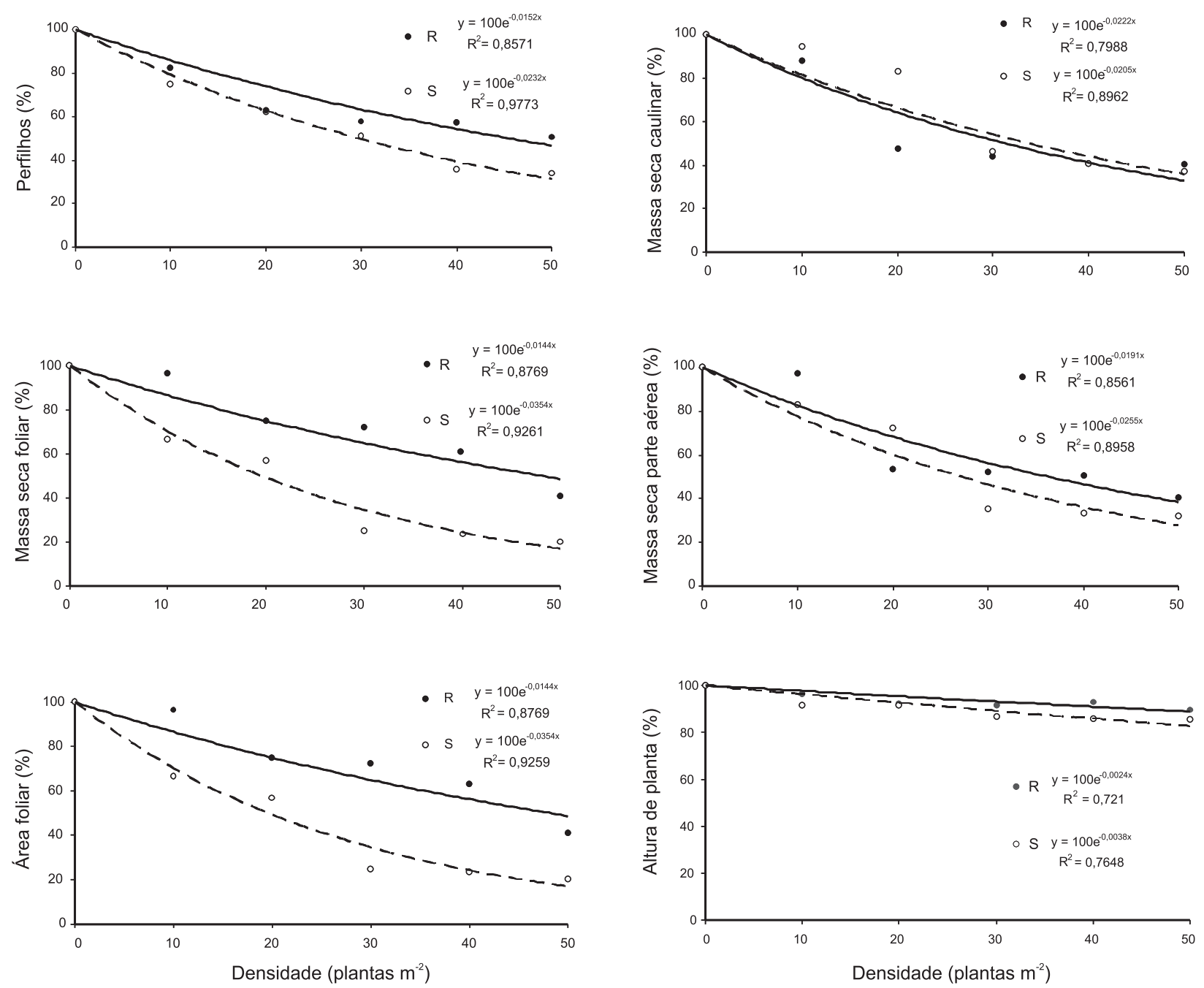

Figura 3 - Porcentagem de perfilhos, massa seca caulinar, massa seca foliar, massa seca da parte aérea, área foliar e altura de plantas isoladas de trigo, competindo com plantas de azevém em diferentes densidades.

(DAE); para o biótipo resistente essa tendência de redução foi mais acentuada. A taxa de crescimento da cultura (TCC), expressa pela velocidade média de crescimento ao longo do período de observação, foi maior para o biótipo suscetível até mesmo nas maiores densidades. Resultados semelhantes para Bidens pilosa foram observados por Christoffoleti et al. (2001), que constataram que biótipos sensiveis dessas espécies a herbicidas inibidores da ALS apresentaram maior taxa de crescimento inicial dos 0 aos 28 dias, quando comparados ao biótipo resistente. Quanto à área foliar específica (SLA), que relaciona a superficie e o peso da folha, representando a espessura desta (Silva et al., 2005), as plantas de azevém do biótipo suscetivel apresentaram folhas mais espessas (maior SLA) que as plantas do biótipo resistente em todas as densidades avaliadas. A maioria dos estudos relatados na literatura sobre a comparação da competitividade entre os biótipos resistente e suscetivel de plantas daninhas têm sido realizados com plantas daninhas da classe Magnoliopsida. A maior parte dessas pesquisas mostra prejuízo para o biótipo resistente em relação ao suscetivel (LeBaron \& Gresse1, 1982). Entretanto, em condições de campo, tem-se observado o domínio dos biótipos resistentes sobre os suscetiveis, embora estes apresentem menor adaptação ecológica. Isso acontece em virtude da alta pressão de seleção provocada pelas constantes eliminações das plantas suscetiveis devido ao uso repetido de um mesmo herbicida (Silva et al., 2007). 

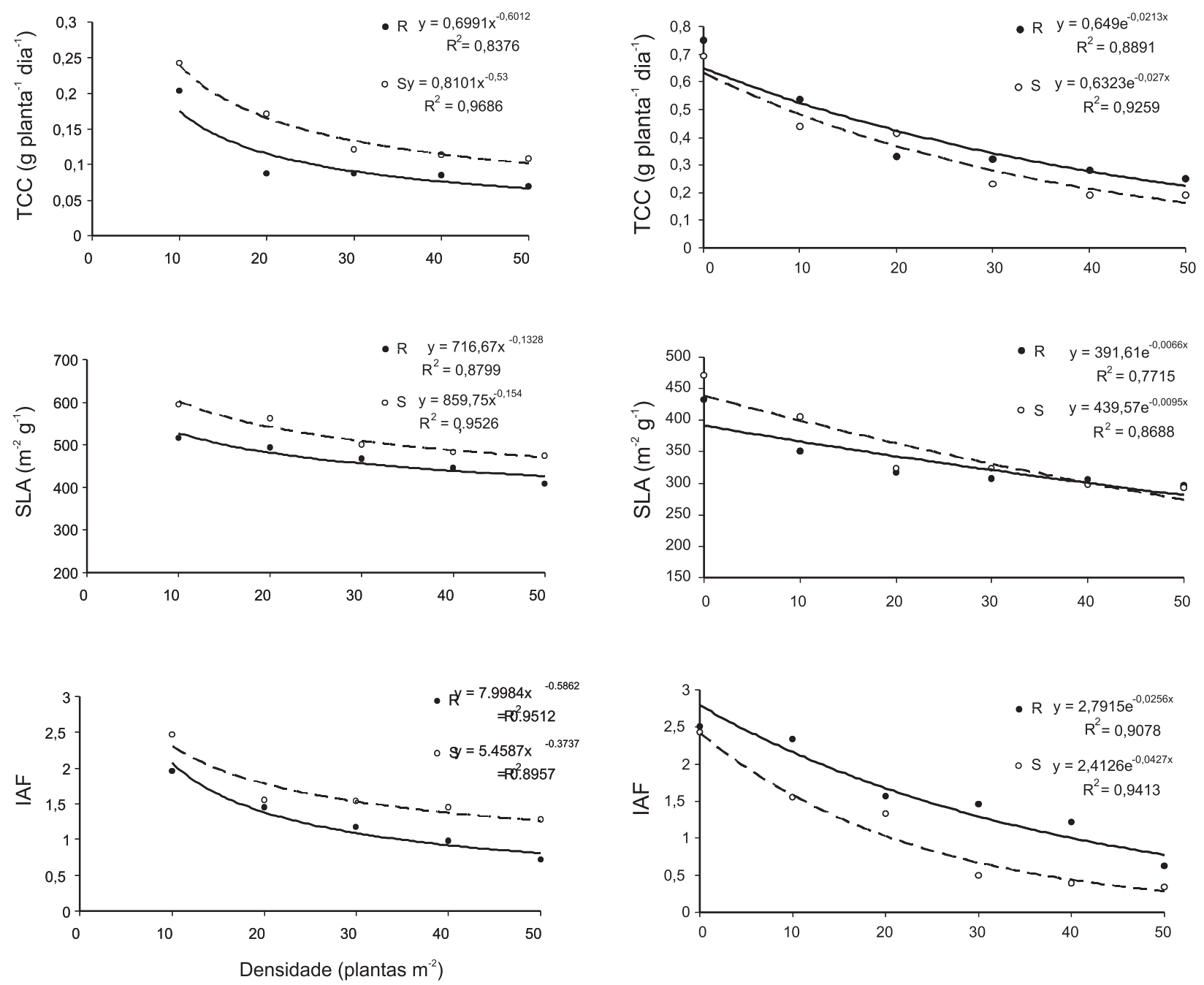

Figura 4 - Taxa de crescimento da cultura (TCC), área foliar específica (SLA) e índice de área foliar (IAF) de plantas de azevém em diferentes densidades, competindo com plantas isoladas de trigo.

Figura 5 - Taxa de crescimento da cultura (TCC), área foliar específica (SLA) e índice de área foliar (IAF) de plantas isoladas de trigo, competindo com plantas de azevém em diferentes densidades.

Esses resultados foram também comprovados por Saari et al. (1994), os quais observaram que, em condições de seleção natural, biótipos com maior adaptação ecológica apresentam, em média, maior produção que biótipos menos adaptados. No entanto, estudos recentes têm evidenciado que biótipos de plantas daninhas resistentes a sulfoniluréias e imidazolinonas (inibidores da ALS) não mostram diferenças de adaptabilidade entre os biótipos resistente e suscetivel (Christoffoleti, 1992).

Com relação às variáveis taxa de crescimento da cultura (TCC), área foliar específica

(SLA) e índice de área foliar (IAF) de plantas de trigo competindo com plantas de azevém em diferentes densidades, observou-se ajuste das curvas ( $p<0,001$ e $p<0,005)$, sendo representadas por modelos exponenciais (Figura 5).

As plantas de trigo mostraram tendência de redução do TCC e IAF com o aumento da densidade de plantas de azevém tanto para o biótipo resistente quanto para o suscetível; contudo, o aumento da densidade de azevém suscetivel provocou maior redução da TCC e IAF das plantas de trigo, quando comparado com o biótipo resistente (Figura 5). Em competição 
com o biótipo suscetível, as plantas de trigo apresentaram maior SLA nas menores densidades de azevém, porém, com o incremento na densidade de plantas de azevém nos dois biótipos, as curvas tenderam a se inverter, e, na maior densidade de plantas suscetivel, esse biótipo apresentou menor SLA que o biótipo resistente (Figura 5).

De acordo com os resultados, pode-se afirmar que existe diferença na capacidade competitiva entre os biótipos resistente e suscetível de azevém. Na maior parte das variáveis estudadas, como altura de planta, massa seca e área foliar, o biótipo suscetivel apresentou menor tendência de redução com o incremento da densidade. Com relação às plantas de trigo, estas mostraram maior redução na maioria das variáveis quando competindo com plantas de azevém do biótipo suscetível. Diante do exposto, concluiu-se que o biótipo suscetivel apresenta maior capacidade competitiva que o resistente. Na ausência da pressão de seleção (não-aplicação de glyphosate), o equilíbrio populacional do azevém pode tender para o biótipo suscetível ao glyphosate, em detrimento do resistente.

\section{LITERATURA CITADA}

AARSSEN, L. W. Ecological combining ability and competitive combining ability in plants: toward a general evolutionary theory of coexistence in systems of competition. Am. Natur., v. 122, n. 6, p. 707-731, 1983.

BALBINOT Jr., A. A. et al. Características de plantas de arroz e a habilidade competitiva com plantas daninhas.

Planta Daninha, v. 21, n. 2, p. 165-174, 2003.

CHRISTOFFOLETI, P. J. et al. Análise comparativa de crescimento de biótipos de picão-preto (Bidens pilosa) resistente e suscetível aos herbicidas inibidores da ALS. Planta Daninha, v. 19, n. 1, p. 75-85, 2001.

CHRISTOFFOLETI, P. J. Growth, competitive ability and fitness of sulfonylurea resistant and susceptible Kochia scoparia. Fort Collins: Colorado State University, 1992. $198 \mathrm{p}$.

ERASMO, E. A. L. et al. Efeito da densidade e dos períodos de convivência de Cyperus esculentus na cultura do arroz irrigado. Planta Daninha, v. 21, n. 3, p. 381-383, 2003.

FERREIRA, E. A. et al. Glyphosate no controle de biótipos de azevém e impacto na microbiota do solo. Planta Daninha, v. 24, v. 3, p. 573-578. 2006.
FLECK, N. G. et al. Competição de azevém (Lolium multiflorum L.) com duas cultivares de trigo. Planta Daninha, v. 3, n. 2, p. 61-67, 1980.

FLECK, N. G. et al. Interferência de Raphanus sativus sobre cultivares de soja durante a fase vegetativa de desenvolvimento da cultura. Planta Daninha, v. 24, n. 3, p. $425-434,2006$

GOLDBERG, D. E.; LANDA, K. Competitive effect and response: hierarchies and correlated traits in the early stages of competition. J. Ecol., v. 79, n. 4, p. 1013-1030, 1991.

JORDAN, N. Prospects for weed control through crop interference. Ecol. Appl., v. 3, n. 1, p. 84-91, 1993

LeBARON, H. M.; GRESSEL, J. Summary of accomplishments, conclusions, and future needs. In: LeBARON, H. M.; GRESSEL, J. (Eds.). Herbicide resistance en plants. New York: John Wiley \& Sons, 1982. p. $349-362$

LEMERLE, D. et al. The potential for selecting wheat varieties strongly competitive against weeds. Weed Res., v. 36, n. 6 , p. 505-513, 1996.

MELO, P. T. B. S. et al. Comportamento de populações de arroz irrigado em função das proporções de plantas originadas de sementes de alta e baixa qualidade fisiológica. R. Bras. Agroc., v. 12, n. 1, p. 37-43, 2006.

PARKS, R. J. et al. Herbicide susceptibility and biological fitness of triazine-resistant and susceptible common lambsquarters (Chenopodium album). Weed Sci., v. 44, n. 3, p. $517-522,1996$

PEREZ, A.; KOGAN, M. Glyphosate-resistant Lolium multiflorum in Chilean orchards. Weed Res., v. 43, n. 1, p. 12-19, 2002.

PITELLI, R. A. Interferência de plantas daninhas em culturas agrícolas. Inf. Agropec., v. 11, n. 129, p. 16-27, 1985.

RADOSEVICH, S.; HOLT, J.; GHERSA, C. Physiological aspects of competition. In: RADOSEVICH, S.; HOLT, J.; GHERSA, C. Weed ecology implications for managements. New York: John Willey \& Sons, 1996. p. 217-301

ROMAN, E. S. et al. Resistência de azevém (Lolium multiflorum) ao herbicida glyphosate. Planta Daninha, v. 22, n. 2, p. 301-306, 2004.

SAARI, L. L. et al. Resistance to acetolactate synthase inhibiting herbicides. In: POWLES, S. B.; HOLTUM, J. A. $M$. Herbicide resistance in plants: biology and biochemistry. Boca Raton: 1994. p. 83-139.

SILVA, A. A. et al. Biologia de plantas daninhas. In: Tópicos em manejo de plantas daninhas. Viçosa, $\mathrm{MG}$ :

Universidade Federal de Viçosa, 2007. 367 p. 
SILVA, A. C. et al. Análise de crescimento de Brachiaria brizantha submetida a doses reduzidas de fluazifop-p-butil. Planta Daninha, v. 23, n. 1, p. 45-51, 2005.

SINCLAIR, T. R. et al. Water use efficiency of field-grown maize during moisture stress. Plant Physiol., v. 56, n. 2 , p. $245-249,1975$.

VARGAS, L. et al. Identificação de biótipos de azevém (Lolium multiflorum) resistentes ao herbicida glyphosate em pomares de maçã. Planta Daninha, v. 22, n. 4, p. 617-622, 2004.
VARGAS, L. et al. Alteração das características biológicas dos biótipos de azevém (Lolium multiflorum) ocasionada pela resistência ao herbicida glyphosate. Planta Daninha, v. 23, n. 1, p. 153-160, 2005.

WEED SCIENCE - INTERNATIONAL SURVEY OF HERBICIDE RESISTANT WEEDS. Disponível em: <http:// www.weedscience.org>. Acesso em: 10 de nov. de 2006.

WORTMANN, C. S. Contribution of bean morphological characteristics to weed suppression. Agron. J., v. 85, n. 4, p. 840-843, 1993 